\title{
MUJER, CONFLICTOS Y MARGINACIÓN EN LA EDAD MODERNA. DOCUMENTACIÓN SOBRE LOS PROCESOS JUDICIALES EN ALICANTE DURANTE EL SIGLO XVIII.
}

\author{
SUSANA LLORENS ORTUÑo (Archivo Municipal de Alicante) \\ VERÓNICA MATEO RIPOLL (Universidad de Alicante)
}

\section{Resumen}

El presente artículo no pretende ser más que un acercamiento al estudio de uno de los grandes, y a la par desconocidos, conjuntos documentales custodiados en los archivos: la documentación de carácter judicial. En este caso, nos aproximaremos a ella a través de la serie de pleitos del Archivo Municipal de Alicante, analizando varios procesos relacionados con mundo femenino, y más concretamente con mujeres pertenecientes a los niveles inferiores de la escala social. De su situación conflictiva y marginal damos cuenta a través de cuatro casos acaecidos durante el siglo XVIII, examinando los diferentes tipos documentales y forma de inicio de las causas en que se ven envueltas.

\begin{abstract}
This article only intends to be an approach to the study of one of the biggest and at the same time least known set of documents kept in the archives: the judicial documentation. In this case, we will try to have a look at it examinig a series of judicial cases of the Municipal Archives of Alicante, analyzing several cases related to the world of women and, particularly, cases with reference to women belonging to the lowest social class. We will be able to deal with their conflicts and social exclusion thanks to the study or four cases that took place in the XVIII century. We will also examine the different types of documents and the way the lawsuits in which they were involved were brought.
\end{abstract}

En el transcurso del siglo XVIII se va a afianzar la identificación del honor personal, y lo fundamental de la existencia privada se concentra en el ámbito familiar. Este, no obstante, puede verse amenazado por las imprudencias de sus propios miembros; para protegerlos del escándalo resultará necesario acudir a la autoridad pública $\mathrm{y}$, en primer lugar, a la del soberano ${ }^{1}$. Sólo esta jurisdicción puede preservar el secreto que el honor familiar exige, y al mismo tiempo, reducir los desórdenes que lo resquebrajan y garantizar la libertad de cada cual en su ámbito particular, contra las imposiciones colectivas de la costumbre. Y es que, ciertamente, el vivir día a día de las personas creaba en ocasiones múltiples tensiones, ya que no siempre se respetaban las reglas jurídicas, peligrando los intereses o

\footnotetext{
${ }^{1}$ Ariès, Ph. y Duby, G. Historia de la vida privada, Madrid, Taurus, 1992, t. 6.
} 
el honor. De ahí la necesidad de tener a punto los mecanismos utilizables en los supuestos de violación de las normas, al objeto de restablecer el Derecho en lo posible y de castigar, si había lugar, las transgresiones del ordenamiento jurídico. Se trataba de prevenir los conflictos sociales y de proporcionar cauces preestablecidos de solución a los mismos ${ }^{2}$.

Es precisamente la nutrida documentación que ha generado dichos quebrantamientos e irregularidades el objeto del presente artículo. La documentación judicial, rica por su variedad y posibilidades de trabajo, nos va a brindar la oportunidad de acercarnos a ciertos desórdenes y transgresiones en que se vio envuelto un colectivo social complejo, el femenino, a través de cuatro expedientes que tienen en común a mujeres encausadas o envueltas en procesos donde son protagonistas. Dicha documentación forma parte del fondo documental de Pleitos que se conserva en el Archivo Municipal de Alicante, topográficamente ubicado en el depósito 1-A, y que consta de 36 legajos. Cronológicamente la serie comienza en el año 1480, con el pleito entre las ciudades de Alicante y Elche sobre el amojonamiento de sus términos --único legajo del siglo XV- y se suceden hasta el año 1833, sumando un total de 1450 expedientes.

La selección efectuada no ha resultado en modo alguno aleatoria; se ha llevado a cabo en la consideración de que los cuatro casos escogidos responden a la realidad de algunos hechos en los que se vio envuelta la mujer durante el Antiguo Régimen; mujeres normalmente situadas en los grupos inferiores de la escala social, procedentes en su mayor parte de ámbitos familiares deprimidos económicamente, lo que explicaría determinadas circunstancias relacionadas con los procesos que se les incoan.

Desde el punto de vista diplomático los pleitos ${ }^{3}$, como documentos múltiples que son, engloban a su vez documentos simples cuya tipología es muy variada; unos serían los derivados de la propia tramitación -caso de los pedimentos, oficios, autos, certificaciones, sentencias, etc.--, mientras que en otros podríamos distinguir los aportados como pruebas --cartas, recibos, inventarios, etc.--. Asimismo algunos de los citados, como es el pedimento, es en sí mismo un documento simple, aunque muchas veces vaya acompañado de otros que refuerzan legalmente la petición -

\footnotetext{
${ }^{2}$ Artola, M. (Dir), Enciclopedia de Historia de España, Madrid, Alianza Editorial, 1988, t. II. Instituciones politicas. Imperio.

${ }^{3}$ López Gómez, P. et al.’Una aportación al estudio tipológico de la documentación judicial del Antiguo Régimen: Los pedimentos", en I Jornadas sobre metodología para la identificación y valoración de fondos documentales de las administraciones públicas, 1992, pp.141-149.
} 
podríamos citar las cartas de poder, a modo de ejemplo--, y que suelen estar incorporados en la causa.

Sabido es que todo proceso judicial sobreviene por un motivo, por alguna cuestión que inicia la causa. Esta se correspondería con el asunto que, siguiendo la clasificación que propone Lorenzo Cadarso ${ }^{4}$, bien pudiera vincularse a motivaciones económicas, o bien a los relacionados con la delicuencia --y más en concreto con el escándalo y alteraciones del orden público--, entre otros.

Así, los dos primeros procesos que pasamos a analizar estarían vinculados al primero de los citados, esto es; la cuestión económica, y principalmente al tema de la propiedad.

\section{PROCESOS POR MOTIVACIONES ECONÓMICAS. EL ESPI- NOSO ASUNTO DE LA PROPIEDAD}

Los motivos económicos siempre han sido un caldo de cultivo especialmente propicio para los conflictos. Dentro de éstos, los procesos judiciales cuyo trasfondo es la propiedad son, sin duda, de los más numerosos. Los dos casos que hemos seleccionado en torno a esta materia tienen, además, un punto y un motivo comunes: la esclavitud y la finalidad crematística. En ambos procesos constatamos un derecho sobre la propiedad que se centra en las personas, a quienes se reclama por ser una posesión adquirida o por la pretensión de enriquecerse comerciando con ellas. Dichos casos son los referidos a la compra-venta de una esclava ${ }^{5}$, así como las acusaciones por fuga de una esclava turca ${ }^{6}$.

\section{Documento $n^{0} 1$ : proceso de desempeño y venta de una esclava.}

La carpetilla que contiene el expediente describe en su portada el contenido del tenor siguiente; en el margen superior derecho figura el año "1714", y a continuación un breve resumen: "Autos de Francisco Hernández, procurador de Estacia Carratalá, viuda vesina de la ciudad de Murcia contra Joseph Carratalá de Joseph, su hermano”. Juez el señor Alcalde Mayor por su Majestad de esta ciudad; Escribano, Juan Bautista

\footnotetext{
${ }^{4}$ En este trabajo hemos seguido el estudio de P. L. Lorenzo Cadarso, La documentación judicial en la época de los Austrias. Estudio archivístico y diplomático. Universidad de Extremadura, 1999, pp.53-54.

${ }^{5}$ A.M.A. Pleitos, Armario 3, Leg. $15 / 13$

${ }^{6}$ A.M.A. Pleitos, Armario 3, Leg.18/30.
} 
Hernández". Los tipos documentales con que se inicia, producto a su vez de los diversos actos, son:

\section{Juicio de primera instancia a pedimiento de parte.}

Denuncia de Francisco Hernández, como procurador de Estacia Carratalá ${ }^{7}$ de la deuda contraída con su hermano, José Carratalá, por haber desempeñado por nueve doblones a una esclava que tenía pignorada a la marquesa de Torre Pacheco.

"Francisco Hernandes, en nombre de Estacia Carratala,/ viuda y vesina de la ciudad de Murcia y en virtud de su poder que testimonio del presento y juro en devida forma, como mejor puedo y laya lugar en derecho y sin perjuhicio de qualquier otro que a mi parte competa de que pro-/testo usar como le convenga. Digo que en virtud de estas dos cartas misivas $^{8}$ por Joseph Carratalá,/su hermano con fecha de nueve de diciembre /del año pasado mil setecientos y nueve y catorse de julio de mil setecientos $y$ dies $^{10}$, que pre-/sento con la misma solemnidad para que le de-/sempenase una esclava que tenia en poder de la marquesa de Torre Pacheco, en nueve doblones /con efecto aviendo la dicha marquesa dado len empeño de dicha cantidad a don Cristo-/val Antonio de Bustos y Carrasco, señor de Cutillas, al susodicho para desempeñar dicha esclava, / (y por aserle merse y buena obra a dicho ermano, /por el y prestados) dio dichos nueve doblones de que /para seguridad de mi parte le entrego dicho don Cristhoval resibo ${ }^{11}$ firmado por dicha

\footnotetext{
${ }^{7}$ Presenta el testimonio del notario Vicente Cerdá del poder que, con fecha 3 de octubre de 1713, le otorgó Estacia Carratalá, residente en Murcia, para que le represente en todas las causas y pleitos.

${ }^{8}$ Como prueba están las dos cartas que José Carratalá envió a su hermana.

${ }^{9}$ En la primera pide que desempeñe a la esclava y que la venda o haga lo que quiera con ella: "Muy Sra. mia la presente loable... con la /salud que io deseo la mia, a dios gracias/, la tengo buena para todo que lo sea desta mayor servicio, lo que por esta se me ofrece, es desirte/ como tengo una esclava enpeñada,/ en cas[a] de la marquesa de Torre Pacheco,/ por nueve doblones en que estimare/ me favorezca en dar los nueve doblones /y sacarla, y ver si la puedes /vender y seno dexarla en por do quiera, y /mira que es mui piquera y ladrona/ y asina estimare que me desempeñe que/ io quedo a la satisfación . A mi ermana/ Raymunda y a las muchachas, muchos/ abrazos y a ti te guarde Dios los /años de tu deseo. Alicante a 9 de diciembre de 1709. /José Carratalá de José",.

${ }^{10}$ La segunda carta dice así: "Hermana mia, tengo recebido dos cartas tuias/ y el no averta respondido a sido de vergüenza /de ver queno te e podido desempeñar en dar los nueve /doblones, ni posibilidad, para poderselos /dar, pues poco me falta para abandonar lesta tierra y irme, pues siempre pidiendo prestado /para poder comer, que si lo vieras te lastimarías/ de mi y asi no. Ai tienes la [e]sclava, la puedes vender/ o empeñar, o aser lo que bien te paresca /de ella que io por ahora no puedo mas. A Raymundal que tengo esta por propia, y que toda laquella ropa que se llevó mía de San Juan del cas[a] de su [h]ija, que an se lo dí e a la ora ma la asen/ pagar a mi, los parientes de Isola Rios, tenga en/ su Santa gloria y la perdona, por amor de Dios/ y no escuses el mandarme que te servire con /todo gusto. Dios te guarde los años de tu deseo/. Alicante, julio a 14 del año 1710. José Carratalá".

${ }^{11}$ Presentan como justificante el recibo firmado por la marquesa de Torre Pacheco en el que se comprueba la entrega de los nueve doblones que se le adeudaban por la esclava.
} 
marquesa /de dicha cantidad que es este que presento con el mismo juramento. $Y$ atento que mi parte /ha requerido al dicho Joseph Carratalá extrajudicialmente repetidas veses para que le pague dichos nueve doblones de a dos escu-/dos de oro cada uno, y así mismo, para que lle buelva y entregue a mi parte las alajas /de plata ${ }^{12}$ que constan de este papel que dexo len su poder por prendas de quatro doblones / que le dio a mi parte quando murió su marido, lo que no ha querido aser sin contiende /de juhicio.

Por tanto y aviendo por presen-/tados dicho poder y mas papeles a vuestra merced, suplico mande comparecer al susodicho y /de baxo juramento sin diferirle cosa al-/guna en el y sin perjuhicio de la prueva, /declara, clara y distintamente confor-/me a la ley y baxo su pena ser cierto lo lexpresado en este escrito. Y que dichas dos cartas son escritas de su puño y letra y lasí mismo el contexto de la memoria /de las partidas donde consta de las alajas /que quedaron en su poder por empeño /de quatro doblones, como son dies cucharas y seis tenedores y de plata que pesaron /veynte onsas; un salero de plata con peso de lquatro onsas, una pilita de dosel para agua /bendita también de plata, que pesava quatro lonsas, una crus de Caravaca grande de /plata sobre dorada que pesava quatro onsas / y media, otra crus con una cadenita de plata /que pesava dos onsas y media, otra crus del plata lque pesava una onsa y dos adarmes y un mondadientes de los mismo.

Y fecha que sea dicha /declaración se me de ella traslado para en su vista pedir mas en forma lo que a mi parte conben-/ga en justicia ${ }^{13}$, que pido protesto las costas, juro ${ }^{14}$ len forma y para ella etcétera. E mando por Licenciado Serrano".

\section{Autos de instrucción del procedimiento.}

El procedimiento sigue su desarrollo con la presentación de las cartas y demás papeles para que las reconozca José Carratalá. El auto lo traslada Francisco Esteban Zamora y Canovas, abogado y a la sazón alcalde mayor de Alicante ${ }^{15}$, estando datado en esta ciudad en nueve de junio de

\footnotetext{
${ }^{12}$ Se aporta la relación de bienes de plata y otras alhajas que entregó a su hermano.

${ }^{13}$ Cláusula de petición genérica, "pedir...en justicia".

${ }^{14}$ Cláusula de juramento que cierra el documento, "juro en forma".

${ }^{15}$ El consistorio establecido tras la Nueva Planta en la ciudad de Alicante quedó estructurado con el nombramiento de un corregidor como presidente, un alcalde mayor como asesor jurídico, y doce regidores. En los municipios valencianos el corregidor debía representar al monarca y al Consejo de Castilla, actuar como delegado del Capitán General en cuestiones militares, representar al intendente como subdelegado de rentas, promulgar ordenaciones municipales y dictar sentencias en primera instancia. Pero, como ha puesto de mani-
} 
1714. En él figura la firma de Juan Bautista Hernández, escribano asignado a la causa, y como tal encargado de dar fe pública del acto.

3. Notificación del auto.

Dos días después, en once de junio, el escribano notifica el auto a José Carratalá, como parte implicada en la causa; y quién en esos momentos se encontraba en su casa, por lo que sería informado mediante notificación personal.

\section{Declaración.}

A continuación se recoge la declaración del acusado, en el que jura "por Dios Nuestro Señor y a una señal de la cruz... dezir verdad", siguiendo la costumbre.

En el interrogatorio se le pregunta si conoce las dos cartas, recibo y memoria que se han presentado como prueba; a lo que contesta reconocer las dos primeras, firmadas de su puño y letra. No obstante afirma desconocer los otros papeles, ni saber quien los ha escrito

"Ni se lacuerda que dicha Estacia Carratalá le aya dado por empeño de los /quatro doblones que supone las prendas /de plata, que expresan dicho pedimiento...".

Por otra parte, asegura haber pagado a la citada Carratalá los 9 doblones; pero, en virtud de lo ordenado en una de las cartas, se quedó con la esclava, ignorando en aquellos momentos su paradero "[no sabiendo] si la ha vendido, o lo que ha hecho de ella".

5. Notificación.

El proceso finaliza con el envío del escribano Juan Bautista Hernández del contenido del auto y la decisión judicial a Francisco Hernández, procurador de Estacia Carratalá, con fecha de doce de junio de 1714. sus obligaciones civiles en segundo plano. Este hecho hizo que se le concediera gran importancia a la figura del alcalde mayor o teniente de corregidor. Dicho cargo normalmente era ejercido por un letrado que actuaba como juez en pleitos y causas civiles y criminales, sustituyendo al corregidor, ya que éste no tenía la preparación jurídica. Vid. Giménez López, E. Militares en Valencia (1707-1808) Alicante, 1990. 


\section{Documento n²: proceso por fuga de la esclava Mariana.}

El segundo expediente que pasamos a describir consta de una carpetilla en la que aparece en el margen superior el año "1718", y a continuación el siguiente resumen: "Autos de Don Melchor Miguel y Sánchez, vezino de esta ciudad, contra Mariana, esclava suya. Juez, el Señor corregidor por su Magestad, y secretario Juan Bautista Hernández". Nuevamente resulta de sumo interés la descripción que nos ofrece la portada, por ser el lugar donde se especifican los elementos identificativos básicos de la causa, las disposiciones de iniciación del proceso, la identificación del demandante contra la acusada, el juez instructor y el escribano.

Los actos jurídicos que principian el proceso, que se inicia con un pedimiento, y los autos correspondientes, son los siguientes:

\section{Juicio de primera instancia a pedimiento de parte.}

Melchor Miguel y Sánchez denuncia la huida de su esclava Mariana de su casa para contraer matrimonio, durante su ausencia y sin su permiso. El documento se inicia con la data crónica y exposición de motivos:

"Que len nueve de noviembre del año pasado mil setecientos /y siete, compré $e^{16}$ de Aniceto Herbás, apothecario, una lesclava ya christiana, que antes se llamava Hisma y /después de ser bautizada Maria Ana, por precio de ochenta ly cinco libras, moneda de este reyno, segun consta por lla escritura ${ }^{17}$ que pasó ante Timotheo Carbonell, escriva-/no, copia de la qual es la que en devida forma pre-/sento, y juro, y como estando yo ausente $y$, sin consentimien-/to mio, segun asi lo juro, haya contrahido matrimonio, ly se aya ausentado de mi casa, lo que es en perjuicio de /mis derechos, por lo que avida y por presentada dicha es-/critura, a Vuestra Ilustrisima, pido y suplico se sirva apremiar a la dicha lesclava, con todo rigor de derecho, para que sirva en mi /cassa y buelva a ella, para que en

\footnotetext{
${ }^{16}$ La escritura de venta de la esclava está fechada el día 9 de noviembre de 1707, y en ella figura la descripción siguiente : " una esclava blanca turca de nació y al present cristiana...de edat... de uns trenta y sis anys, poch mes o menys".

${ }^{17}$ Se presenta como prueba el apoca de 28 de enero de 1708: "Sit omnibus, notum que /Aniceto Hervás, apothecari de /la present ciutat de Alacant,/ habitador ... confessa y en bona veritat /reqoneix, haver hagut y rebut, / y estar content, satisfet y pagat, /del noble don Melchor Miquel /y Sanchez, de dita y present ciutat /de Alacant,.../absent y dels seus de totes aquelles huitanta y cinch /peses de a huit plata doble, per/ dit don Melchor Miquel, la ell degudes, per lo preu de /una esclava nomenada Maria/ Anna,... la qual cantitat ha rebut en con /semblant valor y cantitat, de vi/ negre, que per son orde y conte/ de dit Hervás, y expres consentiment /y voluntat de aquell, a entregat /y lliurat, lo dit don Melchor /Miquel, a Valero Duart, de dital y present ciutat...,/segons que aixi fonch ajustat,/ se havia de pagar y satisfet, /la dita solució y paga de dita lesclava, y valor y preu de aquella..."
} 
esta conformidad pue-/da usar del derecho adquirido en fuerça de dicha compra. /Por ser asi de justicia que pido juro lo necessario y por ello etcétera".

Este recurso sigue el modelo tradicional de petición, ya que nos encontramos con la fórmula: "pido y suplico se sirva apremiar"18. Por su parte, la expresión "Por ser así de justicia" la consideramos un tipo de cláusula de petición genérica que, según Cadarso, son las que cierran todos los documentos peticionarios o alegatorios presentados por los litigantes ${ }^{19}$.

\section{Autos de instrucción del procedimiento.}

Se manda notificar a la esclava Mariana que, a tenor de lo especificado en su contrato de venta, cumpla con lo establecido y regrese a servir, obedeciendo lo expuesto en el pedimiento.

"Por presentada con el instrumento de venta que /refiere notifiquesele a la contenida en el pedimento,//sirva y obedesca, como tal esclava a esta par-/te, sin perjuhicio del uso libre del matri-/monio, con apercibimiento de lo que lugar alla. LLo mandó el Señor Mariscal de Campo, Joseph Antonio de Chaves, oficio Governador, /Corregidor y Justicia mayor por Vuestra Magestad, de esta ciudad de Alicante, su partido y testimonio /con acuerdo de su infrascrito ..... que la firmaron. En Alicante, a ocho de /Marzo de mil setecientos y diez y ocho de que doy $f e^{20} . / "$

\section{Reclamación del pedimiento.}

Ante la negativa de la encausada a obedecer, y haciendo caso omiso a la notificación, Melchor Miguel y Sánchez reitera lo expuesto en el auto que antecede.

"Que haviendo puesto pedimento en el dia ocho /de los corrientes, pidiendo se la apremiase con todo rigor /una esclava suya propria que se llama Mariana, /para que le sirviese, la firmó tambien en su auto del mesmo/ dia, andar se la notificase a la dicha esclava, mandar/ sirviese y obedeciese como tal, sin perjuhicio del uso de /matrimonio que sin mi consentimiento celebró, con lapercebimiento de la que huviese lugar, el qual auto tal/ hizo notorio en el mismo dia...y/ como sin embargo de

\footnotetext{
${ }^{18}$ P. Lorenzo Cadarso, La documentación judicial en la época de los Austrias Op.Cit. Pp.62.

${ }^{19}$ Ibidem, p.66.

${ }^{20}$ Después vienen dos notificaciones sobre el auto que el escribano, Juan Bautista Hernández comunica a la demandada Mariana y al demandante, Melchor Miguel y Sánchez.
} 
haversele notificado el susodicho/ auto, no la haya obedecido y tenia fuga en ella,/ por tanto y acusandole como la acuso la rebeldia y a de ser/ acusada a Vuestra Ilustrisima, pido y suplico ...apremiaria en todo rigor de derecho, el cumplimiento de lo mandado... de justicia etc."

\section{Notificación del auto.}

El juez dictamina en su fallo acusar de rebeldía a la esclava Mariana por no obedecer; al tiempo que le ordena regresar a la casa de su dueño.

"Por presentada, por acusada la rebeldia, apremiésele la la esclava, contenida en estos autos, a que /cumpla lo mandado por el de ocho del corrien-/te, para lo qual sea llevada a la casa del/ dueño, a quien se le haga entrega para que use /de su derecho con la limitación, que en dicho au-/to se previene. Asi lo proveyó el Señor Corregidor //y Justicia Mayor por su Magestad, de esta ciu-/dad de Alicante y su jurisdicción con / acuerdo de su infrascrito. A diez dias del mes de marzo de mil setecientos dies y ocho anos. Lo firmaron ${ }^{21}$ de que doy fe."

\section{Testimonio o fe de la diligencia.}

En cumplimiento del auto, el ministro ordinario de la jurisdicción y el secretario acuden a la casa de la esclava; tras lo cual proceden a entregarla a su dueño, Melchor Miguel y Sánchez.

"En Alicante, en dicho dia, Melchor de Ynesta ${ }^{22}$, ministro lordinario de esta jurisdicción, en cumplimiento del au-/to que antecede, acompañado de mi el secretario, fue a lla casa de morada de Mariana, expresa-/da en el antecedente pedimento. Haviendola /hallado en ella, en la entrada de /dicha casa, la hizo levantar y agarrada la / llevó a la casa de morada, de don Melchor Mi-/guel, vecino de esta ciudad, a quien se la en/tregó, de que doy fe".

El asunto principal que nos ocupa en torno a los dos casos citados, la esclavitud, es un fenómeno que, si bien se ha dado prácticamente en todas las épocas históricas, no ha sido estudiado con la misma intensidad. Así, es mejor conocida en Grecia y Roma que en la edades Media ${ }^{23}$ y Moderna, cuya riqueza bibliográfica es menor y especialmente en esta

\footnotetext{
${ }^{21}$ Aparecen las firmas del corregidor Antonio de Chaves y del citado Boyer ante el escribano Juan Bautista Hernández.

${ }^{22}$ Hay una notificación del escribano Hernández sobre el auto a Melchor de Yñesta, ministro ordinario de esta jurisdicción.

${ }^{23}$ Uno de los estudios más significativos es el clásico de J. Heers Esclavos y sirvientes en la Edad Media, Institució "Alfons el Magnánim", Valencia, 1989.
} 
última, a excepción de los trabajos sobre la esclavitud en América ${ }^{24}$. Lo cierto es que durante el siglo XVIII en España la esclavitud era una institución en declive; no resultaba tan frecuente encontrar seres humanos sometidos a ella, y tenerlos parecía más bien un capricho suntuario, toda vez que eran considerados y tenidos como criados participando en las tareas domésticas, como puede constatarse a través de los procesos narrados.

Una de las razones de ese desconocimiento radica, sin duda, en la desigual o nula atención que la documentación le ha prestado. La fuente prioritaria ha sido hasta la fecha los protocolos notariales, puesto que las distintas escrituras permitían trazar un buen panorama social, económico, jurídico y mental, al estar el esclavo presente en gran cantidad de contratos. La legislación, las ordenanzas municipales, los archivos inquisitoriales, parroquiales, los libros de cofradías ${ }^{25}$, así como los catastros, vecindarios y padrones $^{26}$ han constituido otras de las fuentes consultadas, a las que tenemos que añadir los pleitos judiciales como documentación a la que acudir para futuras investigaciones.

Andalucia es una de las zonas donde el tema más ha llamado la atención de los historiadores, aunque las investigaciones rara vez sobrepasan el siglo XVII. Estudios centrados en los grupos de esclavos negros, mulatos y moriscos, así como turcos y bereberes, importados directamente de Africa o bien capturados en las guerrillas permanentes sostenidas por las plazas españolas del norte de Africa, y destinados fundamentalmente a trabajar en presidios y arsenales ${ }^{27}$. Por lo que hace a la costa mediterránea, y especialmente a la valenciana, si bien hay trabajos pioneros y de envergadura a considerar, están centrados fundamentalmente en los albores de la modernidad ${ }^{28}$, no teniendo la continuación deseada ni en el tiempo ni en el espacio. Es por ello que no sorprende que hasta la fecha la ciudad de Alicante sea tierra prácticamente baldía en estos aspectos.

\footnotetext{
${ }^{24}$ Lobo Cabrera, M. La esclavitud en España en la Edad Moderna en Hispania 176 Vol. L/3. Septiembrediciembre 1990. Pp. 1091-1104

${ }^{25}$ Ibidem, pp. 1094

${ }^{26}$ Por reducirnos a un único ejemplo de estudio basado en estas fuentes citaremos el trabajo de Bravo Caro, J.J. Los esclavos en Málaga a mediados del siglo XVIII. Una minoría en extinción en Baetica 19 (2), 1997. Pp. 83-108.

${ }^{27}$ Como ejemplo de estos estudios andaluces citaremos: Franco Silva, A. La esclavitud en Sevilla y su tierra a fines de la Edad Media Sevilla, 1979; Lora, G. "Notas sobre el comercio de esclavos en Córdoba a fines del siglo XV" en Gades 5, 1980. Pp. 77-83; Carriazo, J. de M. "Negros, esclavos y extranjeros en el barrio sevillano de San Bernardo" Archivo Hispalense XX, 1954. Pp. 130-132.

${ }^{28}$ Cortés Alonso, V. La esclavitud en Valencia durante el reinado de los Reyes Católicos (1479-1515); o bien, Graullera Sanz, V. La esclavitud en Valencia en los siglos XVI y XVII Valencia, 1978.
} 
No obstante, parece, con todas las reservas, que el fenómeno esclavista seguiría las mismas pautas que en el resto del territorio peninsular, es decir; la esclavitud a estas alturas del Setecientos sería fundamentalmente doméstica, con predominio de las mujeres sobre los hombres. Sirvientas dedicadas al gobierno de la casa, ocupándose de las tareas domésticas, amamantando en ocasiones a recién nacidos y haciendo compañia a las viudas. A las primeras de las ocupaciones citadas se dedicaba Hisma, esclava de origen turco, comprada para realizar las faenas del hogar. Cuando ésta decide marcharse de la casa para contraer matrimonio, es denunciada por su propietario; para quien resulta una grave falta el abandono del servicio, así como aprovechar su ausencia para casarse, aunque en ningún momento se opone a que ejerza libremente el matrimonio. Método éste muy utilizado por las mujeres ya que su única vía de escape era el casamiento con un hombre libre, procedente de la ciudad o sus alrededores, lo que decidiría en gran medida su porvenir.

Una de las cuestiones a evidenciar es la conversión de la esclava Mariana, Hisma en origen. Y es que, en ocasiones, la domesticidad creaba una cierta familiaridad con los amos, unos fuertes lazos afectivos que favorecían la integración y la conversión a la fe católica romana, pese a que ésta conllevara otros condicionantes sobre los que no nos vamos a pronunciar. Así las cosas, no es raro que la esclava Mariana, nombre ya cristiano, abrazase la religión católica; como tampoco la insistencia de su dueño por llevarla ante la justicia para que volviese a su domicilio y proseguir con sus trabajos domésticos. Se trataba de una persona sometida a servidumbre, compartiendo un espacio y dedicada a una peculiar convivencia con su dueño -que desconocemos- lo que produciría las lógicas fricciones --y la huida en este caso-- de una convivencia bajo el mismo techo; y en donde amo y criado, pese a esa domesticidad, no siempre alcanzaban la armonía en sus relaciones ${ }^{29}$. El deterioro de éstas llegaba en ocasiones a casos extremos, como se deduce de la primera de las causas analizadas; donde la esclava, cuyo nombre no se menciona en la documentación, es considerada como una mercancía susceptible de trato e intercambios, puesta a disposición del mercado, y a quien al tiempo se tacha de "pícara y ladrona", lo que hace suponer no pocos enfrentamientos en las relaciones, pese a describirse éstas, por lo general, como fluidas y poco conflictivas $^{30}$.

\footnotetext{
${ }^{29}$ Bravo Caro, J.J. Los esclavos de Málaga... Op. Cit. Pp. 99

${ }^{30}$ Ibidem, pp. 102
} 
En definitiva, nos encontramos con evidentes ejemplos de esclavos sometidos a intereses económicos de sus dueños, privados igualmente de sus derechos. En ambos casos la motivación económica, amén del honor masculino en tela de juicio en el segundo, darán pie a sendos procesos judiciales, donde se confunde la esfera de lo público y lo privado, y que generan los mismo tipos documentales tanto diplomáticos como judiciales a tenor del motivo del pleito, iniciados con un pedimiento que se eleva ante el juez y que da pie a abrir la instrucción. Ambos se resuelven a favor de los demandantes.

\section{LOS LITIGIOS POR HERENCIAS}

La reclamación de herencias familiares era, igualmente, causa de litigio. En el caso que pasamos a analizar una mujer, Josefa Pérez, reclama el cobro de la herencia de Bautista Bellido, su marido, ausente de la ciudad de Alicante desde hace nueve años; al tiempo que solicita se le pague lo que se le debía a éste, para así poder mantener a su hija.

\section{Documento n 3: Proceso de rescate de una herencia ${ }^{31}$.}

El tipo documental viene reseñado en la carpetilla mediante la anotación "información" 32 .

\section{1.- Información.}

Comienza con la declaración de la interesada, Josefa Pérez.

\footnotetext{
${ }^{31}$ A.M.A. Pleitos, Armario 3, legajo, 14, expediente, 5.

32 Siguiendo a L. Cadarso, Op. Cit. Pp. 258, "información" es un tipo documental específico de interrogatorio de testigos que el juez lleva a cabo en secreto; es decir, sin comunicación alguna a los litigantes ni a los encausados durante la fase sumaria del procedimiento. Consistía en el interrogatorio con un formulario preestablecido de los testigos de cargo, que estaban obligados a declarar bajo pena de ser condenados por negarse a acatar una orden judicial y a hacerlo sinceramente bajo pena de ser condenados como "testigos calumniosos".

"Tras la expedición del preceptivo auto ordenando la información, se publicaba un bando invitando a todos los testigos que hubieran presenciado los hechos a acudir a la audiencia. El interrogatorio se llevaba a cabo en presencia del escribano de la causa, que levantaba un acta cuidadosa de todas las declaraciones de los testigos. Estos, tras una serie de preguntas de identificación personal, juraban decir la verdad. Cada una de las declaraciones era un acta independiente, validada con las firmas del testigo y del juez y corroborada por el escribano, aunque se cosían todas juntas en un mismo cuadernillo, a menudo con portada y diligencia de cierre independiente. De acuerdo con el secretismo que presidía la fase sumaria de todo proceso penal, este documento, junto con los demás elaborados por el tribunal en esta fase, permanecería secreto y no sería comunicado a los litigantes. De este modo, cuando llegaba la hora de interrogar a los acusados, las llamadas "confesiones", éstos no tenían noticia alguna acerca de la información que el juez había acumulado contra ellos, y sólo algunas breves referencias acerca de las acusaciones vertidas contra ellos."

Hemos considerado oportuno incluir esta aclaración para que puedan apreciarse con una mayor perspectiva los diversos tipos documentales que intervienen en este caso, a diferencia de los expuestos con anterioridad; al tiempo que comprender la brevedad de algunas informaciones en general y del proceso en particular, comparativamente.
} 
"Jusepha Peres, muger que soy de Bautista Bellido, premissal la venia. Digo que respecto de tener el dicho mi /marido derecho y parte a los bienes y herencia de los di-/funtos Bautista Bellido y Jusepha Jordá, sus padres,/ junto Thomás Bellido, su [h]ermano, ambos[h] erederos/ de aquellos y estarle debiéndole algunas personas de esta /ciudad y otras partes ciertas cantidades de moneda y lel dicho Bautista Bellido, mi marido, hallarse ausente de /dicha ciudad y este reino de más de nueve años a esta /parte, sin noticia en donde tenga su asiento y morada Ini le espero que venga tan presto. Pido y suplico a V.M. lque havida información de la ausencia del dicho mi ma-/rido y de la necesidad que tengo de haver a su parte/ los bienes que le tocaran de dichas [h]erencias y de pe-/dir lo que se le debe para mis alimentos y los de /Luisa Bellido, su hija y mia legitima y natural me /mande dar licencia para intentar lo referido, estar en /juizio y hazer los demás autos necesarios para su /buena expedición y administración de sus bienes como más al derecho de aquel y mio, convenga les justicia que pido y para ello etcétera y juro en forma de /derecho etcétera. Sin firma ${ }^{33}$ ".

\section{Autos.}

A ésta le sigue el auto que hace constar la presente información, a la que da curso el alcalde mayor en veinte de diciembre de 1709 .

3. Notificación del auto.

El escribano Hernández da testimonio de la notificación del auto a la afectada Josefa Pérez, el 20 de diciembre de 1709.

4.Testimonio o información de testigos.

Tras lo cual continua con la declaración de los tres testigos que aporta la interesada, y que desde el punto de vista diplomático presentan la misma fórmula:

"En la dicha ciudad de Alicante, en los dias,/ mes y año arriba dichos en cumplimiento del lauto antecedente, la dicha Jusepha Perez, muger de Bautista Bellido, vesina de ella para esta información presento por testigo..., del qual su dicho/ senor alcalde mayor recibió juramento /por Dios Nuestro señor y a una señal de cruz,len forma de derecho,

\footnotetext{
${ }^{33}$ El escribano aclara:” Doy fe que esta parte me requirió con este pedimiento sin firma para presentarlo, por decir no saber firmar".
} 
quien lo hizo y lo cargo del oficio de ser verdad, siendo preguntado/ al tenor del pedimiento que va por /cabesa dixo..."

Declarando en su favor José Llobregat, cirujano, "ser cierto que el marido de esta lleva nueve años ausente"; Bautista Ortega, pintor, "no tener noticias del marido de esta y que jamás lo ha visto"; y confirmando dicha ausencia el tercero de ellos, el sastre Bautista Balair.

\section{Resolución.}

Dos años después, en 28 de abril de 1711, el alcalde mayor resolvió en favor de la petición de Josefa Pérez; fallo que suscribió el escribano, Juan Bautista Hernández.

Los estudios sobre familia y los que se centran en las condiciones de vida de las mujeres, coinciden en considerar el matrimonio como punto de referencia a la hora de definir el estatuto y las funciones de cada sexo dentro de la comunidad doméstica ${ }^{34}$. Ciertamente, la identidad de la mujer a menudo venía marcada por su posición social y familiar respecto del varón; mujer, viuda, madre o hija, son los términos o la calificación social que las definían según su estado ${ }^{35}$. El matrimonio era, por tanto, el estado --casi el único-- en el que las mujeres alcanzan toda su dimensión ${ }^{36}$.

La realidad cotidiana hacía sentir a las mujeres la autoridad del varón, prolongándose esta ideología en el seno de la familia, puesto que jugaba un papel decisivo el control económico que el cabeza de familia detentaba sobre los bienes propios y los gananciales ${ }^{37}$. Ciertamente matrimonio y patrimonio iban unidos, siendo ésta la causa de múltiples desavenencias, y de que los litigios por herencias, derechos y tutelas estallaran a la menor ocasión.

No este el caso que nos ocupa stricto sensu, sí en cambio se trata de un litigio a consecuencia de una herencia en el ámbito del matrimonio, aunque con matices. En esta demanda queda bien patente como Josefa Pérez, abandona por su marido años atrás, al no poder dedicarse a ciertas labores o servicios que hubieran podido contribuir a las necesidades familiares, reclama mediante la vía judicial el cobro de ciertos débitos y atrasos, así como la parte de herencia de sus suegros para poder subsistir junto con su

\footnotetext{
${ }^{34}$ López-Cordón, M.V. “Familia, sexo y género en la España Moderna”, Studia Historica. Historia Moderna 18 (1998), pp. 105-134.

${ }^{35}$ Anderson, B.S. et Zinsser, J.P. Historia de las mujeres. Una historia propia T.I, Barcelona, 1991. Pp. 14

${ }^{36}$ Historia de las mujeres. De la Edad Media al Renacimiento, Arlette Farge y Natalie Zeman (Dir.) Taurus, 1992, pp.570-572.

${ }^{37}$ López-Cordón, M.V. "Familia, sexo y género...” Op. Cit. Pp. 110
} 
hija. La tradición, el marco jurídico, los condicionantes y normas sociales que pesaban sobre la mujer abocándola a una pasiva situación, fueron, como podemos observar, una dura carga de soportar; el pleito, sentenciado a su favor, entraba en este mismo engranaje del código del honor.

\section{LITIGIOS POR DELINCUENCIA, ESCÁNDALO Y ALTERACIÓN DEL ORDEN PÚBLICO}

Como en muchas otras ciudades, en Alicante los escándalos y alteraciones del orden público también han quedado patentes por el testimonio de personas que se vieron afectadas por pequeños conflictos que perturbaron sus vidas. El sumario que ahora nos ocupa se centra en las acusaciones vertidas contra una mujer de nacionalidad irlandesa, imputada por escándalo público ${ }^{38}$.

\section{Documento nº ${ }^{\circ}$ : proceso de escándalo público de Francisca de la Ros-} sa.

En la carpetilla donde se contiene el proceso que pasamos ahora a comentar figura, como viene siendo habitual, la data en el margen superior derecho: "1718 " y un resumen del asunto: "Autos criminales de oficio contra Francisca de la Rossa, de nación irlandesa. Juez el señor alcalde mayor por S.M. de esta ciudad y escribano Andujar".

Lorenzo Cadarso ${ }^{39}$ propone cuatro tipos de procesos, cada uno con un método distinto de apertura. Hemos elegido para nuestro estudio el que sigue, por considerarlo el más apropiado.

Dicho procedimiento judicial se inicia de oficio, como demuestra el informe sobre los hechos que denuncian las autoridades y las declaraciones de los testigos, para dar paso a continuación a la defensa con la declaración de la acusada y sus testigos. La causa finaliza con la resolución judicial en contra de la inculpada.

1. Juicio ordinario en primera instancia iniciados de oficio por el tribunal.

En este caso el juez se da por enterado de la comisión de un posible delito y ordena iniciar las diligencias pertinentes. Comienza el tenor documental con la data tópica y crónica:

\footnotetext{
${ }^{38}$ A.M.A, Pleitos, Armario 3,Leg.17/35.

${ }^{39}$ Lorenzo Cadarso, P.L. La documentación...Op.cit. Pp.84-85.
} 
"En la ciudad de Alicante a quatro de henero de / mil setecientos y diez y siete"

Le sigue la intitulación, en la que aparece el nombre del juez y su identificación jurisdiccional:

" el Señor Don Francisco Estevan / Zamora y Canobas, abogado de los Reales Consejos, al-/calde mayor y theniente correxidor por S.M. de esta /dicha ciudad, su partido y jurisdicción etcétera".

Continua con la exposición de los hechos que le han sido denunciados:

"Dijo que se le /ha dado noticia que poco antes de aora, siendo /como entre las siete y ocho de la noche, del dia /de oy, yendo de ronda el alguacil mayor de es-/ta jurisdicción, con algunos de los ministros ordina-/rios de ellos, asistiendo el presente escrivano la la que estuvieron en la calle llamada del Posti-/guet, se detuvieron a la puerta de una casa,/ por la sospecha y escándalo que se decia dava /una mujer que la habitava, y que haviendo /el dicho alguacil mayor, abierto media puerIta, se vió y advirtió, que en la cozina de / dicha casa estava la referida mujer y que / al lado de ella havia un hombre sentado que la tenia abrasada, y que en la misma / cosina, e inmediato a los expresados estava lotro hombre, al qual y al que tenía abra-/sado a dicha mujer. Para evitar pecados y ofen-/sas a Dios, nuestro señor, les havia preso / y puesto en la carcel real de esta ciudad y encargandoles a su alcayde".

Finalmente, la disposición que ordena la apertura del proceso precedida de una cláusula de corroboración y la validación del documento por el juez, en presencia del escribano:

$" y$ / porque con-/viene averihuar la verdad y con el /castigo desterrar vicios y escandalos de la república, mandó su merced hazer esta /cabeza de processo, y que puesto por el pre-/sente escribano, testimonio de lo que pasó, a su / continuación se hagan las demás diligencias y averihuaciones que convengan y por este auto así lo proveyó y firmó, de que doy fe, Don Esteban Zamora y Cánobas, ante el escribano Francisco Andujar".

2.Declaración de testigos: 
El proceso se abre con las declaraciones de los testigos Francisco Andujar, escribano ${ }^{40}$; Ginés Guerrero, alguacil mayor ${ }^{41}$; Pedro Juan Violat, teniente de alguacil mayor de la jurisdicción ${ }^{42}$; Juan Franco ${ }^{43}$, Pedro de Tebar, Melchor Iñesta y José Franco, ministros ordinarios de esta ciudad ${ }^{44}$.

\section{Interrogatorio:}

Poco tiempo después, en nueve de enero de 1717, se manda tomar declaración a Francisca de la Rossa; la cual, por ser de nacionalidad irlandesa y no expresarse bien en castellano, tuvo que ser auxiliada por el comerciante inglés Daniel Neuland Ducret, quien en su calidad de intérprete juró traducir fielmente.

El interrogatorio se caracteriza por someter a varias preguntas a la acusada, cada una de las cuales va encabezada por la expresión, preguntada; usándose para la respuesta la expresión dijo, y que a continuación pasamos a desarrollar:

Preguntada como se llama, de donde es /vezina y natural, que hedad, estado y mo-/do de vivir tiene, dijo que se llama Francisca de la Rosa, de hedad de treinta y cinco años,/ poco mas o menos, que su patria les la villa de Balabuey, en Irlanda, /que habrá cosa de dos años que vino a esta /ciudad, que vive de su trabajo lavando ropa la sus paisanos y otras

\footnotetext{
40 " Ví y reparé, que en un cuarto que sirve del cosina inmediato a la entrada de dicha casa, / havía sentado un hombre y una mujer a la /qual tenía abrasada el referido hombre, con/ el braso izquierdo, y en el mismo quarto,y cerca de los expresados havia otro hombre, y haviendo entrado en dicha casa, ví tambien como se quitó dicho brazo por la novedad que advirtieron..."

${ }_{41}$ Dijo: "que en la nochel del dia de ayer, salió del ronda acompañado del theniente y los ministros ordinarios... Y al pasar /por la calle del Postiguet, con sospecha del malvivir de una mujer, se pasó a escuchar la la puerta de la casa...". A partir de aquí la declaración coincide con la del escribano".

${ }^{42} \mathrm{Su}$ declaración coincide con la de los otros testigos, pero con las siguientes puntualizaciones: "Y el testigo reparó que se quitó el braso del/ cuello de la mujer, por cuyo motivo, el dicho alguacil mayor, hizo prender y llevar presos a lal cácel real a dichos hombres y a la referida mujer le dijo que ya la tenia prevenida que tratase de vivir bien..."

${ }^{43}$ Declara:" y acosa de entre las siete y ocho oras, pasando por la calle del Postiguet, se paró dicho alguacil mayor/ a la puerta de una casa que habita una irlandesa, en la misma calle; y haviendo abierto media puerta, vió el testigo que en la cosina de dicha casa, havia unal mujer y dos hombres, y que uno de estos tenía abrasada a la referida y lo estuvo un gran rato, asta que entrando la ronda se quitó lel braso del cuello de dicha mujer, y haviendo dado orden para que se llebasen a la cárcel real/ a los dos hombres, les llevó el testigo y los otros, sus compañeros; y en dicha ocasión oyó decir al dicho alguacil mayor, hablando con la referida mujer que se quejava, como ya lo tenía avisado, que viviese bien...".

${ }^{44}$ Los dos testigos coinciden en la explicación de los hechos:" Pasando por la calle del Postiguet, cerca de las ocho oras, se detuvo dicho alguacil mayor a la /puerta de una casa, que esta sita en dicha calle/ y habita una mujer, que ha oido decir ser/ inglesa de nación, y a poco rato habrió medial puerta, y se puso a registrar. Y el testigo/ vió y reparó que en la cocina de dicha casa habia una mujer que es la referida/ inglesa, y dos hombres, uno de los quales la/ tenia abrasada, y estava sentado junto/ y al lado de ella, y estubo en dicha conformidad,/ un buen rato y asta que entró la ronda que entonces que entran y /quitó el brazo de sobre el cuello de la dicha mujer..."
} 
personas y estranje-/ros, aunque expresó su estado, su mer-/ced le calla por la decencia de él y responde.

Preguntada por los dos hombres que esta-/ban en las casas de su morada, al tiempo /que entró en ellas la ronda de su merced,/la noche del dia quatro del corriente, a qué /havian ido y quantas veces, dijo que /uno de dichos hombres es marinero /y que por piedad lo recojía en su ca-/sa de haverle despedido habrá unos quin-/ze dias, con poca diferencia el capitán Ide el navio, en que el referido vino em-//barcado, y que el otro es criado de un cava-/llero irlandés que pasa a Suecia, y que Ino le havia visto, si en la mañana del /dicho dia quatro del corriente, que vino a la /casa de la declarante, para que le lavase /unas camisas para el dia siguiente que /havia de hazer viaje a Valencia donde/se hallava su amo, y a la noche reIferida en que le encontró la ronda /havía vuelto a encargar a la declaran/te, no le hiciese falta en componer dịchas /camisas para la mañana del otro dia, ly que así éste como el dicho marinero /sin a dicho su nación y responde.

Preguntada si sabe que es escándalo y acción desones-/ta que un hombre abraze a una mujer y largue /con ella, y más en lugar retirado y a desora de la /noche, dijo que no sabe ni ha sido asta aora lque en dicha ciudad sea cosa escandalosa que se labrazen hombres y mujeres, porque en su /pais no es escandalo y responde.

Preguntada si es cierto que uno de los dos expre-/sados hombres que supone haverle trahido /las camisas, para que se las lavase tenia abra-/sada a la declarante, y puesto sobre su cuello lel brazo, dijo que precisamente no se acuer-//da, pero es muy factible que al tiempo /y quando llegó la ronda, que le estava en-/cargando le tubiese promptas las camisas,/para la mañana siguiente, pusie-/se su brazo sobre el cuello de la declarante el referido hombre, criado del /cavallero irlandés y responde.

$Y$ en este estado mandó su merced dexar por laora, a esta declaración para continuarla según /conviniere, y el dicho Daniel Neuland Idijo que todo lo que ha declarado, es lo mis-/mo que ha dicho y depuesto la dicha Francisca de la Rosa, y fielmente interpretado... no firmó la referida /por no saber,y este que declaró ser de veinte y ocho años, poco más o menos, lo firmó.

En defensa de la acusada, Esteban Pastor, procurador de causas civiles y criminales, alegó no incitar al escándalo la actitud de la acusada, al 
ser encontrada en la cocina de su casa con dos hombres. Como tampoco resultaba inmoral el que estuviese abrazada a uno de ellos, "ya que es normal entre la gente de esa nación". Su reputación, por lo tanto, no arrojaba dudas, como lo demuestra el hecho de que ningún vecino se hubiera quejado de esta mujer, "casada como lo es y honesta", que no hacía más que relacionarse con unos clientes que había ido a su casa a recoger su ropa, pues se dedicaba al oficio de lavandera. Acto seguido, arremetió contra los denunciantes al difamarla por el hecho de estar abrazada a un hombre en su casa, cuando, según la defensa, podía haber cerrado la puerta si su actitud era tan indecente como alegaban.

\section{Declaración de testigos}

El procedimiento continúa con nuevos testimonios de Ginés Guerrero, Pedro Juan Violat, Juan Franco, José Franco, Pedro de Tebar, Melchor Iñesta; quienes no harán sino ratificarse en la anterior declaración sumaria.

A continuación se da paso a la probanza por parte de Francisca de la Rosa, en la causa que de oficio se sigue contra ella. Su procurador, Esteban Pastor, presenta por testigos a Gaspar Noblés, tratante flamenco ${ }^{45}$; Bartholomé Guirardi, tratante veneciano ${ }^{46}$; el citado Daniel Neuland Dreuvet $^{47}$; Antonio Berenguer, tonelero; y José Galdó, maestro carpintero $^{48}$.

\footnotetext{
${ }^{45}$ Dijo que lo que el testigo sabe ly puede decir, sobre lo que contiene dicha /petición, es, que en Inglaterra, Francia, Alemania y los estados de Flandes, no es cosa escandalosa ni de nota, el abrasarse y besar-/se los hombres y mujeres, antes bien en /dichas provincias es el corriente cortejo y saludo, de los naturales y estrangeros len aquellas, sin que por la referida familia-/ridad aya entre ellos presuncion mala, ly en Inglaterra es mas corriente e intro-/ducido este estilo, y se reputa por grosera ly desatenta, a la mujer que dejara de co-/rresponder, y esto lo sabe el testigo, por que ha corrido /los dichos reynos y ha practicado lo misImo en ellos, como vió lo hazian los demás, /ly también sabe que la dicha Francisca la Rossa, /por cuya parte ha sido presentado vive de su trabaxo, lavando ropa a los de nación /inglesa y otras personas y estrangeros y no ha loido decir que aya dado ni de mal exem-/plo, antes bien todo el tiempo que habita en lesta ciudad, que a su entender serán unos dos años con poca diferencia, la conoce el testigo,ly la reputa y tiene por muger onrrada y de /buen vivir y esto mismo ha ohido dezir a sus /vesinos, sin cosa en contrario y aora ha sabi-/do que el motivo de haversele fulminado co-/sa, ha sido el que la ronda la encontró en su /casa con dos hombres y que uno de ellos, le Itenia puesto el braso sobre el cuello y que este /ha ohido desir fue a que le lavase unas cami-/sas, la dicha Francisca, la Rosa, la qual asi mes-/mo ha ohido desir que es casada. Y que esto /que lleva declarado es lo que sabe y puede desir,/lo qual es la verdad en cargo de su juramento, I/fecho y vajo el mismo siendo preguntado por /las generales de la ley, dijo que no es pariente,/amigo intimo, ni enemigo de la referida, ni le Itocan las demás generales que le han sido de-/claradas que solo desea que se determine lesta causa conforme a justicia, y que es de /hedad de treinta y nueve años, poca más ó menos, ly lo firmó con su merced de que doy fé".

${ }^{46} \mathrm{Su}$ declaración coincide con la del comerciante flamenco, aunque destaca lo siguiente: "el testigo como morador que es en la misma calle, serca de la Pescaderia, jamás ha visto desonestidad alguna en la referida Francisca, de la Rosa, ni ha oido desir mal de ella, ni quexar de su modo de vivir a los vesinos más sercanos...".

${ }^{47}$ Su declaración es muy parecida a las anteriores aunque incide en que Francisca de la Rosa vive de su trabajo
} 
5. Sentencia:

Tras las oportunas deliberaciones Francisco Esteban Zamora resuelve en contra de la inculpada

"En la ciudad de Alicante a treinta y uno de mar-/zo, de mil setecientos y diez y siete. El Señor Don/ Francisco Esteban Zamora y Cánobas, abogado de los /Reales Consejos Teniente Corregidor y Alcalde Mayor, por su majestad/de esta ciudad, su partido y jurisdicción, haviendo /visto estos autos criminales con-/tra Francisca de la Rosa ${ }^{49}$, dijo que atento a lo /que de ellos alegado y justificado, resulta de /vía de condenar y condenó a la susodicha en ldos años de destierro, de esta ciudad y su goberna-/ción, preciso el uno y el otro voluntario a este /juzgado, que ha de cumplir con apercibimiento /de imponerles doblados en veinte y/cinco ducados vellon, aplicados para la camara /de su majestad y gastos de justicia ${ }^{50}$ por mitad y en llas costas de esta causa reservada su tasación la este juzgado, y por este, su auto definitivo /administrando justicia, así lo juzgo, pronuncio y mando, siendo testigos Pedro de Tebar y José /Franco, de esta ciudad, vecinos y moradores",

Condenándola a la pena de destierro, para el que se fijará un plazo y un ámbito geográfico concretos ${ }^{51}$.

La mujer recluida, guardiana del honor de la familia y dedicada con exclusividad a sus deberes domésticos y religiosos, se corresponde con una imagen y una proyección muy acuñadas en la época, y aún en tiempos posteriores. Sus refugios domésticos añadirían una intimidad a la presencia de la mujer, una privacidad considerada aparentemente inmóvil por la historiografía tradicional ${ }^{52}$.

\footnotetext{
lavando ropa a los naturales y extranjeros, especialmente ingleses y que él como ha frecuentado su casa puede decir que nunca ha visto que fuera una persona de mal vivir.

${ }^{48}$ Sus declaraciones coinciden con las de los demás, y comentan que entre los afincados extranjeros es normal que tengan ese tipo de demostraciones afectivas y que conocen a la acusada hace poco más de un año, a raíz de que se fuera su marido.

${ }^{49}$ Con fecha de 1 de abril de 1717 , se le notifica el auto definitivo a la procesada Francisca de la Rosa, en presencia de su procurador Esteban Pastor y de su traductor.

${ }^{50}$ Con fecha de 22 de mayo de 1717, Francisco Esteban Zamora declara que una vez vista la sentencia de estos autos, ante los que la acusada no ha apelado, mandó su ejecución que consistió en la cobranza de la pena pecuniaria y de las costas del juicio, siendo embargados sus bienes.

${ }_{51}^{5}$ P.L.Lorenzo Cadarso La documentación judicial en la época de los Austrias... Op. Cit. Pp 57-58.

${ }^{52}$ No obstante los estudios que han proliferado de una década aproximadamente a esta parte, en palabras de M.V. López-Cordón: " Consecuencia de la participación activa de las mujeres en el ámbito de la investigación histórica y del deseo de reparar una omisión, el estudio de su presencia efectiva en las sociedades del pasado, y sus implicaciones, se revela como una de las corrientes historiográficas más enriquecedoras de los últimos años" en Familia, sexo y género... Op. Cit. Pp. 106
} 
El silencio, la discreción y el recato se erigieron en los atributos que debían poseer las mujeres modélicas ${ }^{53}$; su quebranto y el desprecio de la norma otorgarían voz a las desenvueltas. Esta soltura alcanzaba diversos grados de desconsideración social, en función de las "liberalidades" manifiestas y probadas de tales mujeres ${ }^{54}$. Entre quienes transgredieron la norma, mereciendo la calificación de "mujer escandalosa" o "mujer de mala vida", según los testimonios de delatores y jueces, encontramos a Francisca de la Rossa; quien, al parecer, no ejercía la prostitución en lugares específicos destinados a ello, como había sido habitual tiempo atrás, sino en su casa, de manera clandestina --como queda dicho-- ante la situación de desamparo, miseria y necesidad en que se vio envuelta tras la "desaparición" de su marido ${ }^{55}$. Nos encontramos, pues, ante uno de los perfiles más típicos de situación y estado de las féminas dedicadas -0 , tal vez, abocadas-- a la prostitución; mujeres que vivían solas, habitualmente forasteras, alejadas temporalmente de sus maridos, ejerciendo unas tareas lavandera, en este caso- propicias a los encuentros y tratos con gente. "Actividades" por las que cobraba algún dinero como complemento a una economía en absoluto saneada, sino más bien cercanas o inmersas en la pobreza $^{56}$.

En una sociedad como la del Antiguo Régimen en donde el respeto a las normas de conducta rige la vida de las personas, nos hace pensar que resulta lógica la actitud tomada por la Justicia. En consonancia con la mentalidad de la época, los estamentos alicantinos fueron proclives al rechazo. El hecho de que una mujer extranjera y con el marido ausente, como Francisca la Rossa, admitiera hombres en su casa estaba muy mal visto. Pese a las declaraciones en su defensa, incluidas las suyas propias, donde la acusada decía acogerlos como clientes puesto que se dedicaba de oficio de lavar la ropa, la condenarán por "mal comportamiento". Sabido es que reglas de conducta muy precisas señalaban el camino por donde podían desplazarse las mujeres; si las quebrantan, se colocaban en dudosa situación y, por lo tanto, susceptibles de ser castigadas por la sociedad. No obstante,

\footnotetext{
${ }^{53} \mathrm{M}$. Vigil ha constatado mediante el estudio de los sermonarios como se proponía un tipo de mujer recatada, silenciosa, humilde, virtuosa, devota, etc. en "La vida de las mujeres en el Barroco" en Actas de las primeras jornadas de investigación interdisciplinaria Seminario de Estudios de la Mujer- UAM, 1982. Pp. 151-165

${ }^{54}$ Candau Chacón, M.L. "Prostitutas y desarraigadas en la Sevilla del Antiguo Régimen" en El Trabajo de las mujeres. Pasado y presente. Seminario de Estudios Interdisciplinarios de la Mujer-Universidad de Málaga. Tomo II. 1996. Pp. 237-251.

${ }^{55}$ En el proceso no se argumentan los motivos por los que se encuentra ausente el marido desde hace un año. Posiblemente este hecho esté relacionado con la idea que expone M.L. Candau en su artículo citado en torno al "silencio constatado"; esto es, silencios protectores, lagunas intencionadas en la documentación que no buscaban sino defender la honorabilidad masculina. Op. cit. Pp. 245

${ }^{56}$ Candau Chacón. M.L. "Prostitutas y desarraigadas..." Op. Cit. Pp. 247
} 
hemos de observar la impresión de benignidad que, pese a todo, subyace en la sentencia. La moderación del castigo se hace patente si consideramos que el destierro resultaba una pena "menor" frente a la condena carcelaria; correctivo sin duda influenciado por la falta de pruebas tangibles contra la acusada, a quien tan sólo se le pudo apercibir por ciertos "desarreglos morales".

Y es que la legislación civil sobre delitos sexuales trató con mayor severidad a las mujeres que a los varones. Durante la Edad Media, sin embargo, la prostitución se toleraba como un mal necesario. El rigorismo moral barroco que imperaría desde el Concilio de Trento daría un giro a este asunto, al ordenar la supresión de mancebías y casas públicas y considerar dichas actividades como pecaminosas, lo cual llevó inexorablemente a la clandestinidad a quienes a ello se dedicaban ${ }^{57}$. No debe extrañarnos, pues, que en aras de esa moralidad la legislación haga hincapié en ese intento por controlar y restringir a las prostitutas; aunque es, sin duda, en el ámbito municipal donde se encuentra la actividad más importante ${ }^{58}$.

\footnotetext{
${ }^{57}$ Ibidem, p. 239.

${ }^{58}$ A lo largo de los siglos XVI a XVIII se van a ir promulgando una serie de leyes pensadas para abrir cada vez más la distancia entre las mujeres honestas y las deshonestas, y más tarde para eliminar del todo la prostitución. Los códigos legales de principios de la época moderna nos revelan una visión parcial y poco clara del status de la mujer en la España del Antiguo Régimen. Tan sólo a fines de siglo se abrieron a la mujer las ocupaciones gremiales. Asimismo, una ley aprobada durante el reinado de Carlos III alude a la educación femenina, preveyéndose en 1768 establecimiento de escuelas para niños de ambos sexos. Actas IV Jornadas Investigación Interdisciplinar. Ordenamiento jurídico y realidad social de las mujeres. Siglos XVI a XX. Seminario de Estudios de la mujer. Universidad Autónoma de Madrid, 1986.
} 